\title{
An Evaluation of Treatment Strategies for Head and Neck Cancer in an African American Population
}

\author{
DN Ignacio ${ }^{1,2}$, JJ Griffin $^{3}$, MG Daniel ${ }^{1}$, MT Serlemitsos-Day ${ }^{1}$, FA Lombardo ${ }^{1}$, TA Alleyne ${ }^{4}$
}

\begin{abstract}
Objective: This study evaluated treatment strategies for head and neck cancers in a predominantly African American population.

Methods: Data were collected utilizing medical records and the tumour registry at the Howard University Hospital. Kaplan-Meier method was used for survival analysis and Cox proportional hazards regression analysis predicted the hazard of death.

Results: Analysis revealed that the main treatment strategy was radiation combined with platinum for all stages except stage I. Cetuximab was employed in only $1 \%$ of cases. Kaplan-Meier analysis revealed stage II patients had poorer outcome than stage IV while Cox proportional hazard regression analysis $(\mathrm{p}=0.4662)$ showed that stage I had a significantly lower hazard of death than stage IV (HR $=0.314 ; \mathrm{p}=0.0272$ ). Contributory factors included tobacco and alcohol but body mass index (BMI) was inversely related to hazard of death.
\end{abstract}

Conclusions: There was no difference in survival using any treatment modality for African Americans.

Keywords: African American, cetuximab, combination-therapy, head and neck cancer, survival

\section{Evaluación de las Estrategias del Tratamiento para el Cáncer de Cabeza y Cuello en una Población Afroamericana \\ DN Ignacio ${ }^{1,2}$, JJ Griffin ${ }^{3}$, MG Daniel ${ }^{1}$, MT Serlemitsos-Day ${ }^{1}$, FA Lombardo ${ }^{1}$, TA Alleyne ${ }^{4}$}

\begin{abstract}
RESUMEN
Objetivo: Este estudio evaluó las estrategias del tratamiento para los cánceres de cabeza y cuello en una población predominantemente afroamericana.

Métodos: Se recopilaron datos utilizando historias clínicas y el registro de tumores del Hospital Universitario Howard. Se utilizó el método de Kaplan-Meier para el análisis de supervivencia, y el análisis de regresión de riesgos proporcionales de Cox para predecir los riesgos de muerte.

Resultados: El análisis reveló que la estrategia principal para el tratamiento fue la radiación combinada con platino para todas las etapas, excepto la etapa I. Se empleó cetuximab en sólo 1\% de los casos. El análisis de Kaplan-Meier reveló que los pacientes de etapa II tuvieron resultados más pobres que los de la etapa IV, mientras que el análisis de regresión de riesgos proporcionales de Cox $(\mathrm{p}=0.4662)$ mostró que la etapa I tenía un riesgo de muerte significativamente menor que la etapa IV $(H R=0.314 ; \mathrm{p}=0.0272)$. Los factores contribuyentes incluyeron el tabaco y el alcohol, pero el indice de masa (IMC) fue inversamente proporcional al riesgo de muerte.

Conclusiones: No hubo diferencias en la supervivencia con ninguna de las modalidades de tratamiento para los afroamericanos.
\end{abstract}

Palabras claves: Afroamericano, cetuximab, terapia de combinación, cáncer de cabeza y cuello, supervivencia

West Indian Med J 2013; 62 (6): 504

From: ${ }^{1}$ College of Pharmacy, Howard University, $23004^{\text {th }}$ Street NW, Washington, DC, 20059 USA, ${ }^{2}$ School of Pharmacy, Faculty of Medical Sciences, The University of the West Indies, St Augustine, Trinidad and Tobago, ${ }^{3}$ College of Dentistry, Howard University, $230044^{\text {th }}$ Street NW, Washington, DC 20059 USA and ${ }^{4}$ Biochemistry Unit, Faculty of Medical Sciences, The University of the West Indies, St Augustine, Trinidad and Tobago.

West Indian Med J 2013; 62 (6): 504
Correspondence: Dr D Ignacio, School of Pharmacy, Faculty of Medical Sciences, The University of the West Indies, St Augustine, Champs Fleurs, Trinidad and Tobago. E-mail: diane.ignacio@sta.uwi.edu 


\section{INTRODUCTION}

Head and neck squamous cell carcinomas (HNSCCs) refer to those cancers occurring in the oral cavity, oropharynx and larynx (1). The American Cancer Society estimated 52140 new head and neck cancer diagnoses and 11460 deaths attributable to these cancers in the United States of America (USA) in 2011 (2). Globally HNSCCs represent approximately $3 \%$ of all cancers diagnosed in men, and $2 \%$ diagnosed in women (1).

The incidence and related mortality of HNSCC has increased over the past decades, despite advances in diagnostic and therapeutic techniques $(3,4)$. Its incidence is three times higher among men, and more common in African American populations than Caucasian populations $(5,6)$. It is reported that African Americans present at younger ages with a higher incidence of advanced stages and often inoperable disease which is associated with poor survival outcomes even after treatment $(1,6-8)$. Within the USA, the estimated five-year survival rate for patients with oral cancer is approximately $60 \%$ depending on the tumour site (9), however, it is only $45 \%$ for blacks and $65 \%$ for whites (10); the five-year survival rate for the Caribbean is undocumented.

Several risk factors have been found to be associated with HNSCCs. The relationship between alcohol consumption, tobacco use and HNSCCs has been clear for many years, and remains one of the main risk factors $(3,7-14)$. Research results have found that the consumption of alcohol coupled with the use of tobacco produces a synergistic effect increasing the likelihood of developing $\operatorname{HNSCC}(4,15)$. Other known aetiologic factors include poor oral hygiene, genetic susceptibility, chronic exposure to certain industrial agents and infection with specific subtypes of human papillomavirus [HPV] $(1,4,8,14)$.

Once a patient is diagnosed, the lesion is staged using the American Joint Commission on Cancer (AJCC) tumour/ node/metastasis (TNM) system (1). The TNM system combines information concerning the extent of anatomic tumour, and the spread of disease into staging that provides estimates of survival, although according to some (16), this approach has limited prognostic value. The comprehensive histopathologic staging is considered by others $(3,4)$ as a more important determinant of postoperative management and prognosis prediction. Ultimately, the prognosis of head and neck cancers depends on the characteristic of the tumour, as well as on multiple host factors $(17,18)$.

The management of HNSCCs during the 1960s and up to the 1980s consisted primarily of surgery and radiation therapy, but with the advances in therapeutic regimens, the treatment of choice of localized, advanced HNSCC is chemoradiation $[\mathrm{CRT}](1,19-21)$. The introduction of the antiepidermal growth factor receptor monoclonal antibody cetuximab recently showed the potential of improving the results of CRT. This drug was demonstrated to increase overall survival when combined with radiotherapy alone (22), or when used in combination with fluorouracil (23-26).
Although previous studies have shown that compared to Caucasians, African Americans have a lower survival rate $(15,27-29)$, few if any have investigated whether the new advances in treatment, and in particular the new combination chemotherapy altered this situation. Howard University Hospital (HUH) services a large urban African American population and thus provides an excellent opportunity to evaluate HNSCC treatment strategies in African Americans. This preliminary study considered the demographics of patients diagnosed with HNSCC, who attended the HUH for the four-year period January 2004 through December 2007. This study aims to retrospectively report the management of $\mathrm{HNC}$ in a single oncology centre in a predominantly African American population.

\section{SUBJECTS AND METHODS}

This retrospective study evaluated the treatment experience of patients aged 18 years and older, diagnosed with HNSCCs at HUH between January 2004 and December 2007. Relevant approval from the Howard University Institutional Review Board was obtained. Data were collected utilizing medical records and information from the tumour registry at HUH. Study variables defined for analysis included: race, gender, primary site of tumour, TNM staging, histological grade, date of diagnosis, age at diagnosis, history of comorbid disease, tobacco and alcohol use, treatment received and date of death or last follow-up. Treatment groups included radiation only, combined radiation and chemotherapy, no treatment and other. Chemotherapy was considered as treatment using a platinum-based regimen, either cisplatin or carboplatin with or without fluorouracil and/or cetuximab. Patients without date of diagnosis or tumour stage were excluded from analysis.

\section{Statistical analysis}

Descriptive statistics including means and frequencies were used to describe all variables. To test associations between nominal study variables, Chi-square and Fisher exact tests were utilized. In cases where multiple comparisons were analysed, Bonferroni's adjustment was used to correct for a Type I Error. To graphically and statistically ascertain the differences in survival between the study groups (treatments, gender, race/ethnicity, tumour site, etc), Kaplan-Meier curves and log-rank analyses were performed. Cox proportional hazards regression analysis was also conducted to further assist in predicting the hazard of death. Data were analysed using the SAS statistical package (version 9.2, SAS Institute, Cary, NC). Statistical significance was considered at $p<$ 0.05 .

\section{RESULTS}

Social and clinical characteristics of the patients are listed in Table 1. The most common primary location of HNSCC was the pharynx $(35 \%)$ followed by larynx $(32 \%)$ with the tongue, oral cavity, parotid and multiple locations making up 
the remainder (33\%) [Fig. 1A]. Of those diagnosed, the vast majority, 92\%, exhibited squamous cell carcinoma; adenocarcinoma accounted for 3\% and sarcoma for 1\% (Fig. 1B).

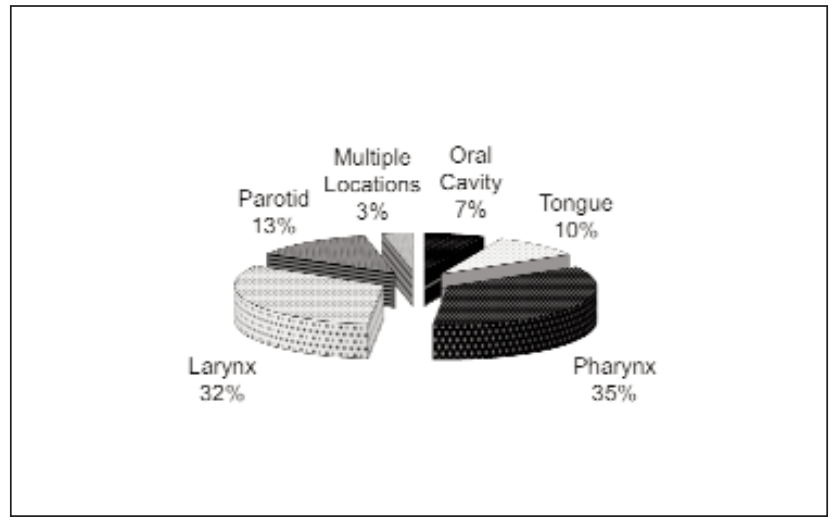

Fig. 1A: Primary site of cancer at diagnosis.

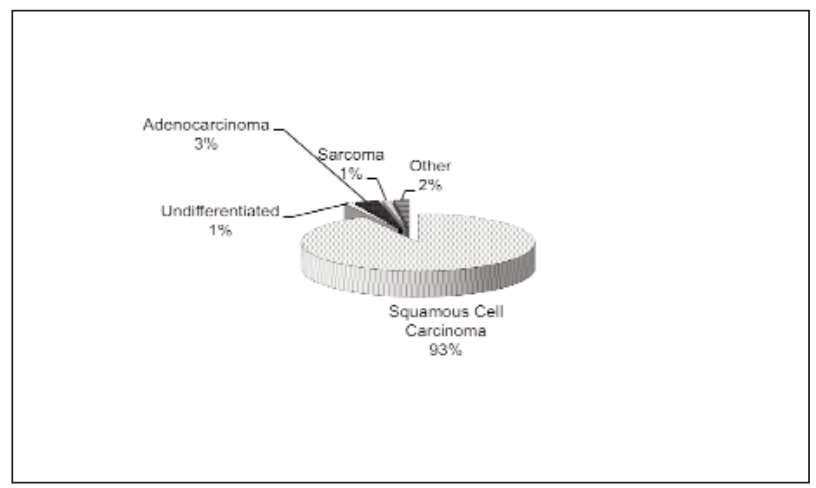

Fig. 1B: Distribution of carcinomas according to the tumour type.

Histological analysis of the biopsy specimen showed $44 \%$ as poorly differentiated tumours and another $40 \%$ as moderately differentiated tumours. At the time of diagnosis, the majority of patients, $62 \%$, were classified as stage IV; $15 \%$ were at stage I and another $14 \%$ at stage III (Fig. 2A).

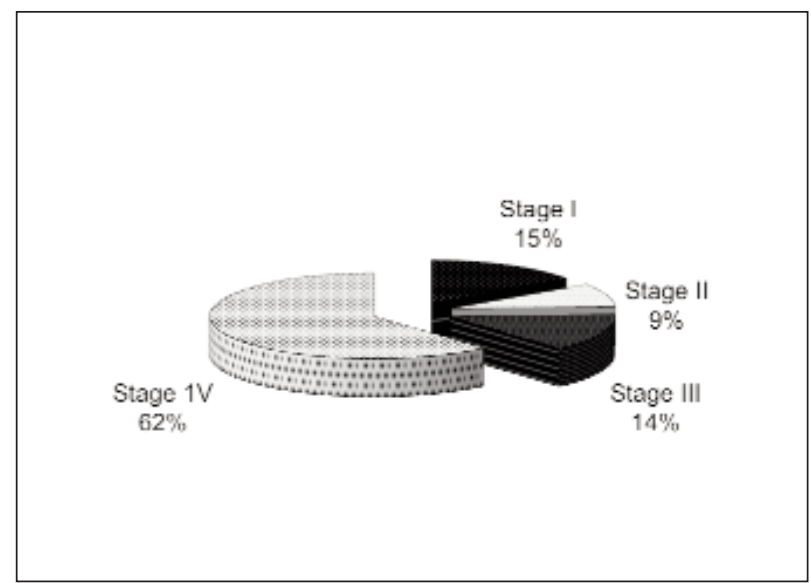

Fig. 2A: Cancer staging at diagnosis.
Overall, the primary treatment modality was radiation therapy only which accounted for $37 \%$. Radiation used in conjunction with combination chemotherapy which included platinum based drugs was received by $23 \%$ of patients while $22 \%$ of patients received no treatment (Fig. 2B). Only $1 \%$ of

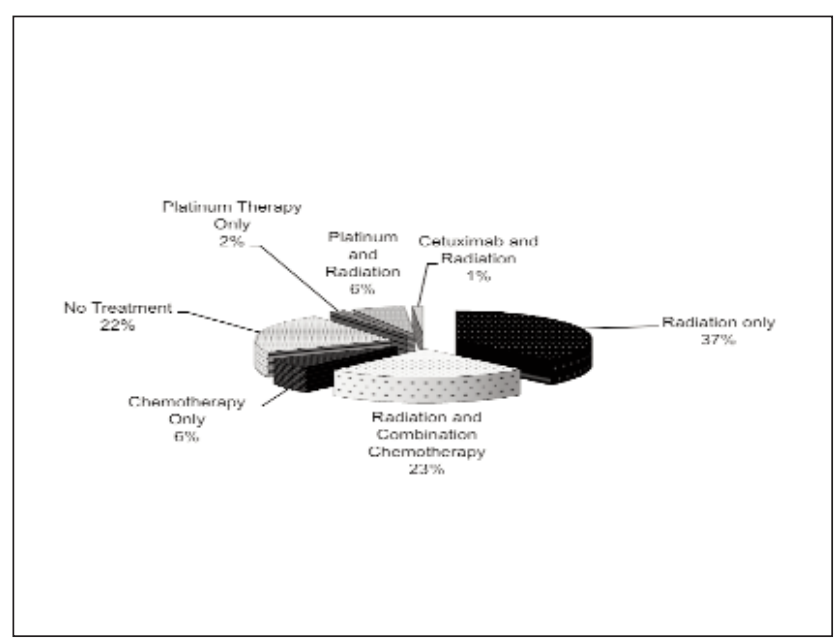

Fig. 2B: Modes of cancer treatment.

patients received cetuximab. In the evaluation of staging and treatment (Table 2), 50\% of stage I patients received no treatment and the remaining 50\% had radiation only. About $44 \%$ of stage II patients received radiation treatment only, 14\% had combination therapy and $29 \%$ had no treatment. Stages III and IV patients had the most variation in treatment modalities. In the Stage III group, $27 \%$ had radiation only, $36 \%$ combination therapy, $18 \%$ no treatment and the remaining 19\% received other therapy (Table 2). For the stage IV, the majority, (35\%), received radiation only, $27 \%$ had combination therapy, $10 \%$ received platinum therapy and $15 \%$ received no treatment (Table 2 ).

Table 1: Social and clinical characteristics of the patients

\begin{tabular}{cc}
\hline \multicolumn{1}{c}{ Patient variables } & $\begin{array}{c}\text { Mean (SD) } \\
(\mathbf{n}=\mathbf{9 1})\end{array}$ \\
\hline Age at diagnosis - mean year (SD) & $59.8(12.11)$ \\
Gender - n (\%) & \\
Male & $63(69.2)$ \\
Female & $28(30.8)$ \\
& \\
Race - n (\%) & $86(95.4)$ \\
African American & $5(5.5)$ \\
Other & $22.21(5.5)$ \\
Body mass index (BMI) - n (\%) & $73(80.2)$ \\
Tobacco use & $64(70.3)$ \\
Alcohol use & \\
Histologic type & $38(43.7)$ \\
Poorly differentiated & $35(40.2)$ \\
Moderately differentiated & $2(2.3)$ \\
Well differentiated & $12(13.8)$ \\
Not specified or other & \\
\hline
\end{tabular}


Table 2: Treatment of head and cancer by stage

\begin{tabular}{lcccc}
\hline $\begin{array}{l}\text { Treatment } \\
\text { approach }\end{array}$ & Stage I (\%) & Stage II (\%) & $\begin{array}{c}\text { Stage III } \\
\mathbf{( \% )}\end{array}$ & $\begin{array}{c}\text { Stage IV } \\
\mathbf{( \% )}\end{array}$ \\
\hline $\begin{array}{l}\text { No treatment } \\
\text { Radiation only }\end{array}$ & 50 & 29 & 18 & 15 \\
Combination & - & 44 & 27 & 35 \\
Platinum & - & 14 & 36 & 27 \\
& & - & - & 10 \\
\hline
\end{tabular}

\section{Multivariate analyses}

Poorly differentiated histology was found to be associated with the use of alcohol $(p=0.00040)$ and tobacco $(p=$ 0.0017 ). Similarly, moderate histological grade was found to be associated with the use of alcohol $(p=0.0011)$ and tobacco $(p=0.0037)$. Both tobacco and alcohol use were associated with an increased risk of death $(\mathrm{HR}=2.123)$ but the unadjusted Cox proportional hazard models detected an inverse relationship for body mass index (BMI) $[\mathrm{HR}=0.921$, $p=0.0095]$.

Comparison of the survival curves of treatment modalities (Fig. 3A) showed that survival was not significantly influenced by differences in the treatment regimens. The multivariate Cox proportional hazard regression analysis (log-rank test $p=0.4662$ ) showed that individuals diagnosed with stage I had a significantly lower hazard of death than individuals diagnosed with stage IV $(\mathrm{HR}=0.314 ; p=$ 0.0272). In assessing the overall survival, stage I $(n=14)$ had the highest median survival whereas stage IV had the lowest outcome. By way of contrast, the Kaplan-Meier curves suggest that stage II patients had a poorer outcome than stage IV (Figs. 3A and B).

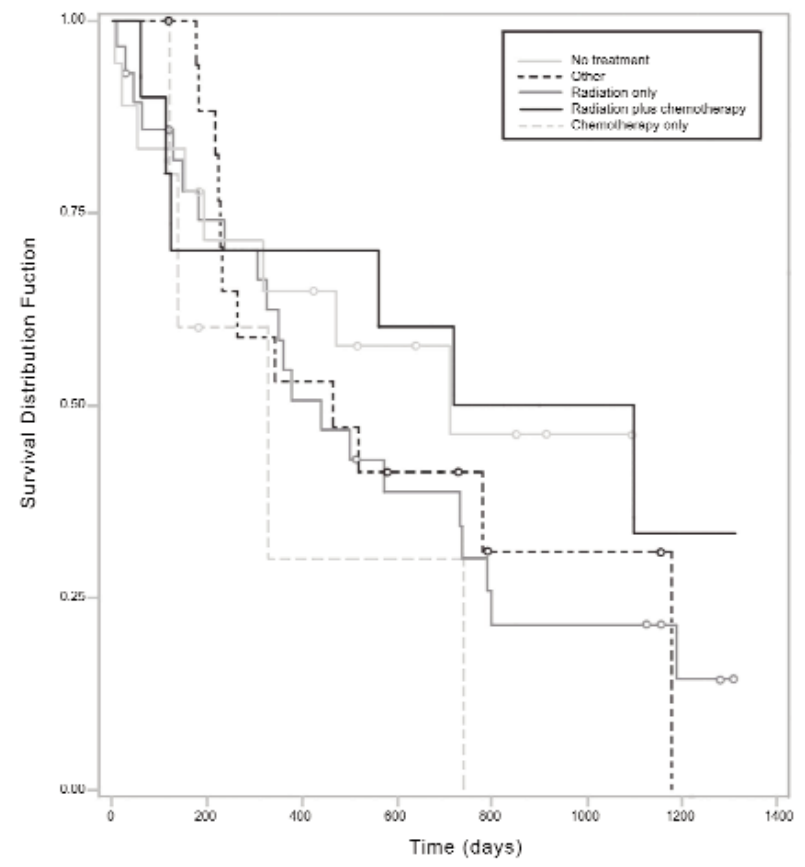

Fig. 3A: Kaplan-Meier plots for survival in patients according to treatment category.

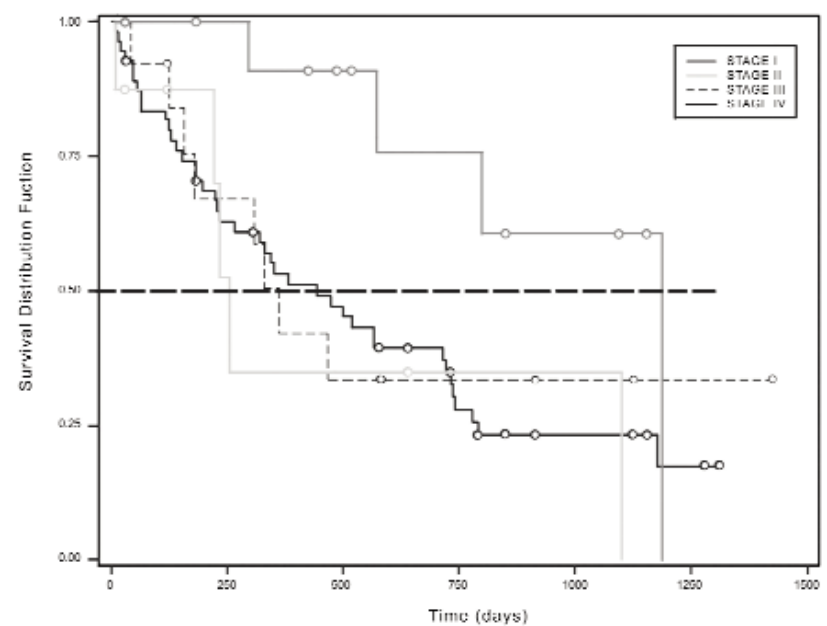

Fig. 3B: Kaplan-Meier plots for survival in patients stratified by stage at diagnosis.

\section{DISCUSSION}

Head and neck squamous cell carcinomas of the oral cavity, which include the oropharynx and larynx, are the sixth most common cancers worldwide with an estimated annual burden of 633000 cases and 355000 deaths (30). Within the USA, the American Cancer Society estimated that for 2011, there would have been 52140 new cases and 11460 deaths attributable to these cancers (2). In particular, the disease has proven to be a death sentence for persons of African descent, as patients in this group respond poorly to treatment $(1,27)$. Several studies have shown that radiation when combined with platinum-based chemotherapy improves survival of HNSCC patients $(1,20-22)$. In recent years, it has been shown that cetuximab, a monoclonal antibody which inhibits binding to epidermal growth factor, increases overall survival when combined with radiotherapy alone (24) or when used with the platinum-fluorouracil (23).

In light of the forgoing, the study uncovered two surprising findings. Analysis of the HUH records revealed that between 2004 and 2007, less than 50\% of the HNSCC patients received chemotherapy, $22 \%$ had no treatment at all and a mere $1 \%$ of patients received cetuximab (Fig. 2B). It could be that cost may have been a major factor in deciding the treatment regimen, as the combination of chemotherapy and radiation is more expensive than radiation alone. Both the 1989 American Cancer Society Report (31) and a study conducted by Molina et al (27) reported that low socioeconomic status among the poor and African Americans impacts negatively on the survival of cancer patients in these two groups. For both groups, a lack of adequate insurance and a lack of affordability of the most appropriate treatment, whether it be chemotherapy or surgery, lead to poorer survival rates. In addition to the cost factor, it has been reported that poor patients, when diagnosed with cancer, often adopt an attitude of resignation to imminent death, and do not always seek medical attention $(27,31)$. In this study, the 
Kaplan-Meier curves (Figs. 3A and B) indicated that persons diagnosed with stage II had a poorer survival than those diagnosed with stage IV. This is not consistent with normal cancer prognosis where stage IV is expected to have the worst of all outcomes $(6,17)$. This finding could be attributed to the poor attitude adopted by blacks in the USA when diagnosed with cancer as previously mentioned $(27,31)$. Indeed, one in five patients in this study received no treatment. The question now arises, how can these trends and attitudes be changed for the better?

Consistent with the findings of many other studies (3, $7-9,11,13-15)$, our study revealed that both tobacco use and regular consumption of alcohol increased the risk of death, however, we were unable to say definitively whether there was a synergistic effect as previous reported $(4,9,11)$. Interestingly, our study revealed that there was an inverse relationship between BMI and hazard of death. This finding is in keeping with that of Liu et al (30) who evaluated oral cancer, Dray et al (33) who evaluated colorectal cancer and others (32).

There may be two possible explanations for the inverse relationship between BMI and hazard of death. In the first instance, HNSCC patients usually experienced difficulty eating and swallowing and therefore nutritional intake decreases dramatically. In such circumstances, those patients with BMIs that are above the accepted norm would have a better prognosis as they could make use of their body's abundant stores of energy. In a similar vein, it has been established that treatment of cancer, whether by surgery, radiation or chemotherapy, involves the destruction of large numbers of normal cells. Following treatment, individuals may recover if regeneration of the destroyed cells occurs. Here again, for HNSCC sufferers where the practicality of maintaining good nutrition is difficult, those with above normal BMIs would be at an advantage as they could use their excess fat stores to meet energy and carbon needs.

In conclusion, our study points to the need for earlier diagnosis, more education and use of a wider range of treatment modalities in order to improve overall outcomes for African Americans and blacks in general suffering with HNSCC. It also suggests that before the commencement of cancer therapy, a period of over-nutrition might be beneficial for $\mathrm{HNC}$ patients with normal and below normal BMIs.

\section{ACKNOWLEDGEMENTS}

The authors wish to thank Dr Mary Maneno and Ms Alfreda Woods from Howard University, Washington, DC and $\mathrm{Mr}$ Michael Khan from Centre for Medical Sciences Education, Faculty of Medical Sciences, The University of the West Indies, St Augustine Campus. This work would not have been possible without their kind cooperation and support.

\section{REFERENCES}

1. Goodwin WJ, Thomas GR, Parker DF, Joseph D, Levis S, Franzmann E. Unequal burden of head and neck cancer in the United States. Head Neck 2008; 30: 358-71.

2. American Cancer Society. Cancer facts and figures 2011. Atlanta: American Cancer Society; 2011 [cited 2012 Aug 6]. Available from: http:/www.cancer.org/acs/groups/content@epidemiologysurveillance/ documents/document/acspc-029771.pdf

3. Arduino PG, Carrozzo M, Chiecchio A, Broccoletti R, Tirone F, Borra $\mathrm{E}$ et al. Clinical and histopathologic independent prognostic factors in oral squamous cell carcinoma: a retrospective study. J Oral Maxillofac Surg 2008; 66: 1570-9.

4. Woolgar JA. Histopathological prognosticator in oral and oropharyngeal squamous cell carcinoma. Oral Oncol 2006; 42: 229-39.

5. Hayat MJ, Howlader N, Reichman MW, Edwards BL. Cancer statistics, trends and multiple primary cancer analyses from the Surveillance, Epidemiology and End Results (SEER) Program. Oncologist 2007; 12: 20-37.

6. Settle K, Posner MR, Schumaker LM, Tan M, Suntharalingam M, Goloubeva $\mathrm{O}$ et al. Racial survival disparity in head and neck cancer results from low prevalence of human papillomavirus infection in black oropharyngeal cancer patients. Cancer Prev Res 2009; 2: 776-81.

7. Gourin CG, Podolsky RH. Racial disparities in patients with head and neck squamous cell carcinoma. Laryngoscope 2006; 116: 1093-1106.

8. Moore RJ, Doherty DA, Do KA, Chamberlain RM, Khuri FR. Racial disparity in survival of patients with squamous cell carcinoma of the oral cavity and pharynx. Eth Health 2001; 6: 165-77.

9. Duffy SA, Ronis DL, McLean S, Fowler KE, Gruber SB, Wolf GT et al. Pretreatment health behaviors predict survival among patients with head and neck squamous cell carcinoma. J Clin Oncol 2009; 27: 1969-75

10. Ullman CD, Herlan LC, Shavers VL, Stevens JL. A population-based study of therapy and survival for patients with head and neck cancer treated in the community. Cancer 2012; 118: 4452-61.

11. Blot WJ, McLaughlin JK, Winn DM, Austin DF, Greenberg RS, Preston-Martin S et al. Smoking and drinking in relation to oral and pharyngeal cancer. Can Res 1988; 48: 3282-7.

12. Morse DE, Kerr R. Disparities in oral and pharyngeal cancer incidence, mortality and survival among black and white Americans. J Am Dent Assoc 2006; 137: 203-12.

13. Forastiere A, Koch W, Trotti A, Sidransky D. Head and neck cancer. N Engl J Med 2001; 345: 1890-1900.

14. Stingone JA, Funkhouser WK, Weissler MC, Bell ME, Olshan AF. Racial differences in the relationship between tobacco, alcohol, and squamous cell carcinoma of the head and neck. Cancer Causes Control 2013; 24: 649-64. Epub 2012 Jun 7.

15. Hashibe M, Brennan P, Chuang SC, Boccia S, Castellsague X, Chen C et al. Interaction between tobacco and alcohol use and the risk of head and neck cancer: pooled analysis in the International Head and Neck Cancer Epidemiology Consortium. Cancer Epidemiol Biomarkers Prev 2009 18: 541-50.

16. Chandu A, Adams G, Smith ACH. Factors affecting survival in patients with oral cancer. Int J Oral Maxillofac Surg 2005; 34: 514-20.

17. Baatenburg de Jong RJ, Hermans J, Molenaar J, Briaire JJ, le Cessie S. Prediction of survival in patients with head and neck cancer. Head Neck 2001; 23: 718-24.

18. Bundgaard T, Bentzen SM, Wildt J, Sørensen FB, Søgaard H, Nielsen JE. Histopathologic, stereologic, epidemiologic and clinical parameters in the prognostic evaluation of squamous cell carcinoma of the oral cavity. Head Neck 1996; 18: 142-52.

19. Garavello W, Spreafico R, Somigliana E, Gaini L, Pignataro L, Gaini M. Prognostic influence of gender in patients with oral tongue cancer. Otolaryngol Head Neck Surg 2008; 138: 768-71.

20. Pignon JP, le Maître A, Maillard E, Bourhis J; MACH-NC Collaborative Group. Meta-analysis of chemotherapy in head and neck cancer (MACH-NC): an update on 93 randomized trials and 17,346 patients. Radiother Oncol 2009; 92: 4-14. 
21. Numico G, Franco P, Cristofano A, Migliaccio F, Spinazzé S, Silvestris $\mathrm{N}$ et al. Is the combination of cetuximab with chemo-radiotherapy regimens worthwhile in the treatment of locally advanced head and neck cancer? A review of current evidence. Crit Rev Oncol Hematol 2013; 85: 112-20. Epub 2012 Jun 27.

22. Bonner JA, Harari PM, Giralt J, Cohen RB, Jones CU, Sur RK et al. Radiotherapy plus cetuximab for locoregionally advanced head and neck cancer: 5 year survival data from a phase 3 randomized trial, and relation between cetuximab-induced rash and survival. Lancet Oncol 2010; 11: 21-8.

23. Vermorken JB, Mesna R, Rivera F, Remenar E, Kawecki A, Rottey S et al. Platinum-based chemotherapy plus cetuximab in head and neck cancer. N Engl J Med 2008; 359: 1116-27.

24. Vermorken JB, Herbst RS, Leon X, Amelial N, Baselga J. Overview of the efficacy of cetuximab in recurrent and/or metastatic squamous cell carcinoma of the head and neck in patients who previously failed platinim-based therapies. Cancer 2008; 112: 2710-19.

25. Specenier PM, Vermoken JB. Current concepts for the management of head and neck cancer: chemotherapy. Oral Oncology 2009; 45: 409-15.

26. Lee K, Strauss M. Head and neck cancer in blacks. J Natl Med Assoc 1996; 86: 530-4.
27. Molina MA, Cheung MC, Perez EA, Byrne MM, Franceschi D, Moffas FL et al. African American and poor patients have a dramatically worse prognosis for head and neck cancer: an examination of 20,915 patients. Cancer 2008; 113: 2797-2806.

28. Ragin CC, Langevin SM, Marzouk M, Grandis JR, Taioli E. Determinants of head and neck cancer survival according to race. Head Neck 2011; 33: 1092-8.

29. Ferlay J, Shin HR, Bray F, Forman D, Mathers C, Parkin DM. Estimates of worldwide burden of cancer in 2008: GLOBOCAN 2008. Int J Cancer 2010; 127: 2893-917.

30. Liu SA, Tsai WC, Wong YK, Lin JC, Poon CK, Chao SY et al. Nutritional factors and survival of patients with oral cancer. Head Neck 2006; 28: 998-1007.

31. American Cancer Society. A summary of the American Cancer Society Report to the Nation: cancer in the poor. CA Cancer J Clin 1989; 39: 263-5.

32. Berclaz G, Li S, Price KN, Coates AS, Castiglione-Gertsch M, Rudenstam CM et al. Body mass index as a prognostic feature in operable breast cancer: the International Breast Cancer Study Group experience. Ann Oncol 2004; 15: 875-84.

33. Dray X, Boutron-Ruault MC, Bertrais S, Sapinho D, BenhamicheBouvier AM, Faivre J. Influence of dietary factors on colorectal cancer survival. Gut 2003; 52: 868-73. 